\title{
Buckling Analysis Of Rectangular Plates With Cutouts And Partial Edge Compression
}

\author{
N. Raghu Prasad ${ }^{1}$, Jeeoot Singh ${ }^{2}$ \\ Mechanical Engineering Branch, Birla Institute of Technology Mesra, Ranchi, Jharkhand ${ }^{1,2}$
}

\begin{abstract}
In the present paper, buckling behavior of rectangular plates with cutouts at different locations and subjected to partial edge compression is investigated. The plate is modeled and results are obtained using ANSYS. Buckling behavior of plates is investigated for simply supported. The work is further extended for different kinds of partial edge compressions. Partial edge compression is applied in such a way that total load on plate remains same for each case. Several numerical results depicting the non-dimensional buckling load for rectangular plates are presented in the form of figures and tables. In order to check the accuracy of the present method, the results are compared with those existing in the literature. The effect of span to thickness ratio and boundary conditions on the buckling load is presented.
\end{abstract}

Keywords: Plate, Buckling, cutout, Partial edge loadings.

\section{INTRODUCTION}

In the structural applications like aeronautical, mechanical and civil structures different cutouts shapes are provided to reduce the weight and for passing the electrical wirings etc. Static structural behavior of rectangular plates with and without cutouts has been studied by the many research scholars using different kind of shear deformation theories and numerical methods. In this paper we are going to study the Partial edge loading which is a kind of nonuniform edge loading. Figure 1 is shows the rectangular plate member under partial edge loading condition.

"When some percentage of part of the edge is kept free from the load, this type of loading is known as partial edge loading" In the literature from the past oldest paper published on buckling behavior of plate under partial edge loading is due to Singh and Sundersen (1998). In that paper two kinds namely Type - I and

Type -II of partial edge loading has been studied for simply supported Plates. Figure 2 shows the two kinds of partial edge loading.

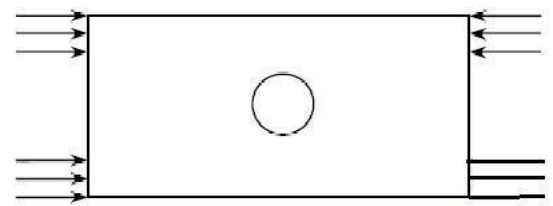

Figure 1:- Partially loaded Plate
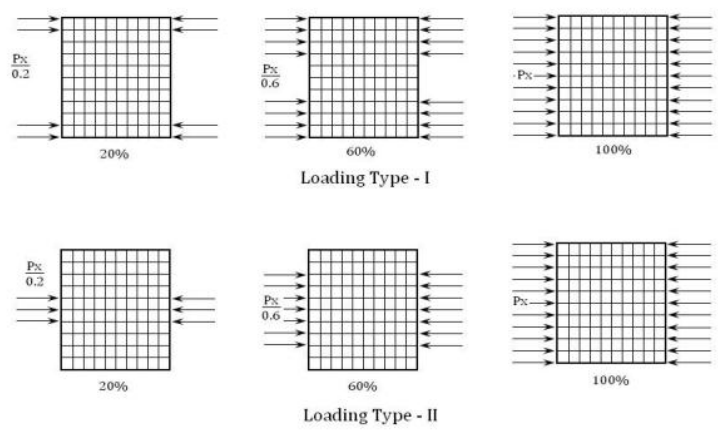

Figure 2:- Type of loading studied in given paper for plates

\section{TYPES OF MESH REFINEMENTS IN FEM}

There are the mainly two kinds of mesh refinements used in FEM to get the accuracy. One is known as p-method and other one is known as h-method. Increase in number of element of same order known as h-method where as increase in order of element is referred as p-method as shown in Figure 3.
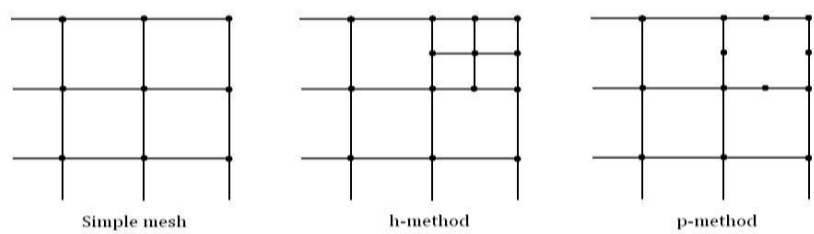

Figure 3:- Types of refinements in FEM

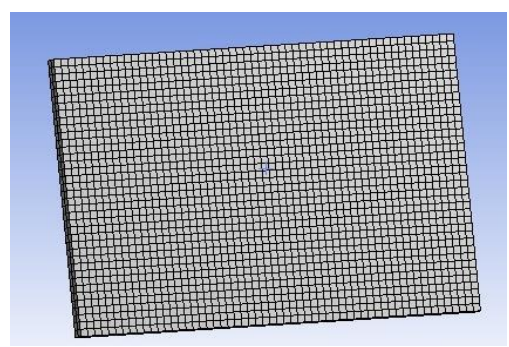

Fig 5: Mesh file of plate without cut out

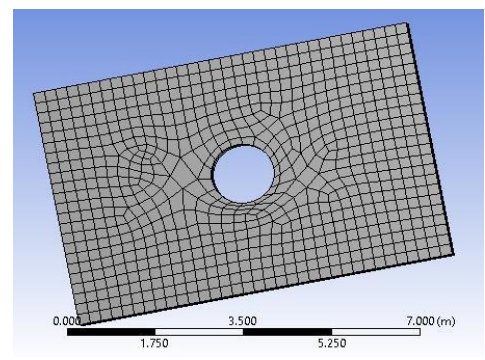

Fig 6: Mesh file of plate with cutout 


\section{Plate DimenSiONS AND MATERIAL}

\section{PROPERTIES}

The dimensions of plate and materials properties were taken as follow

Isotropic Plate

$\mathrm{a}=150 \mathrm{~mm}$

$\mathrm{b}=300 \mathrm{~mm}$

Thickness, $\mathrm{h}=10 \mathrm{~mm}$

Material Properties

Modulus of Elasticity, $\mathrm{E}=210 \mathrm{GPa}$

Poisson's Ratio, $v=0.3$

\section{RESULTS AND DISCUSSION}

For any of the numerical solution it is utmost necessary to check the convergence for solution. Here Table 1 shows the convergence for mesh size of rectangular plate.

We are going for type -1 loading conditions for simply supported (SSSS).

Table 1:- Buckling Load for SSSS plate subjected to full and partial edge loading in uniaxial loading for type $-\mathrm{I}$ for $\mathrm{b} / \mathrm{h}=100$

\begin{tabular}{|c|c|}
\hline $\begin{array}{c}\text { Initial applied load } \\
\mathrm{N} / \mathrm{m}\end{array}$ & $\begin{array}{c}\text { \%age loading } \\
\text { of edge }\end{array}$ \\
\hline 5 & 20 \\
\hline 2.5 & 40 \\
\hline 1.66 & 60 \\
\hline 1.25 & 80 \\
\hline 1 & 100 \\
\hline
\end{tabular}

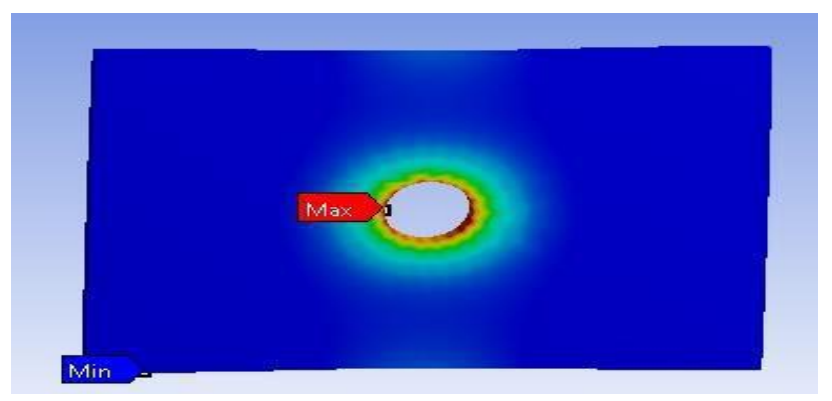

Fig : 20\% Loading (13.5 KPa max)

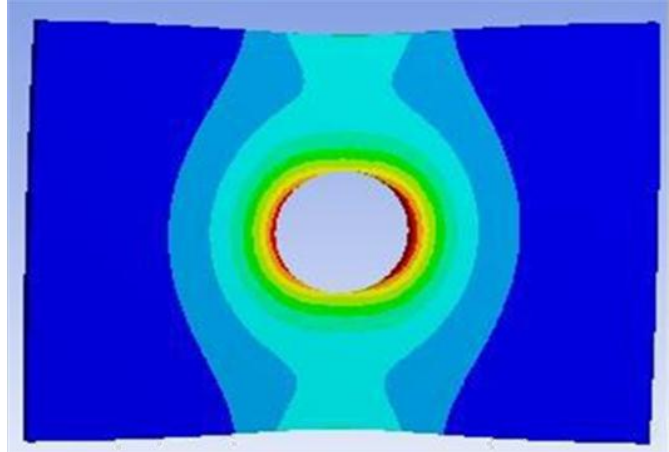

Fig: 40\% Loading (13.239 KPa max)

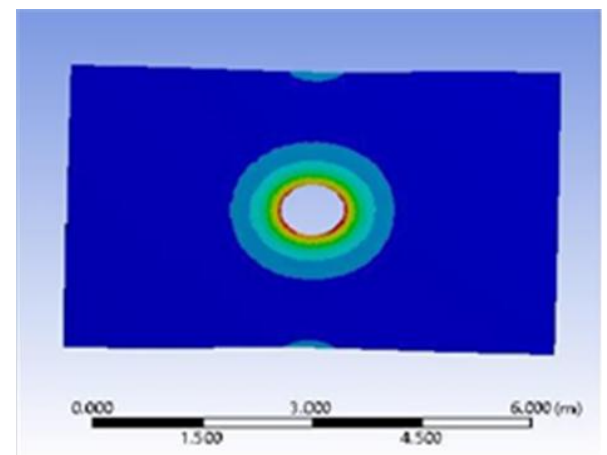

Fig: 60\% Loading (13.791 KPa max)

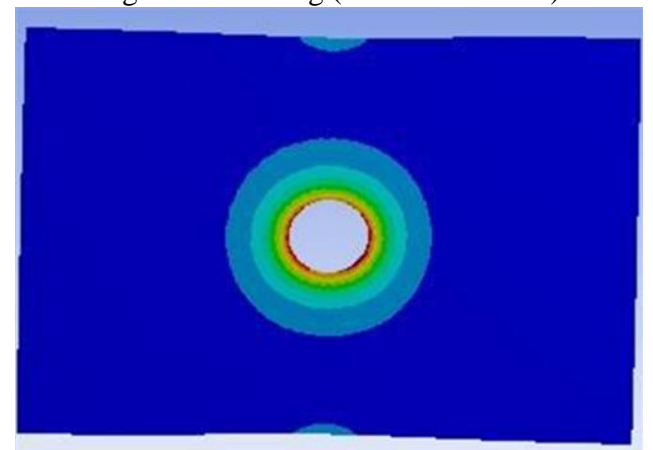

Fig: 80\% Loading (13.587 KPa max)

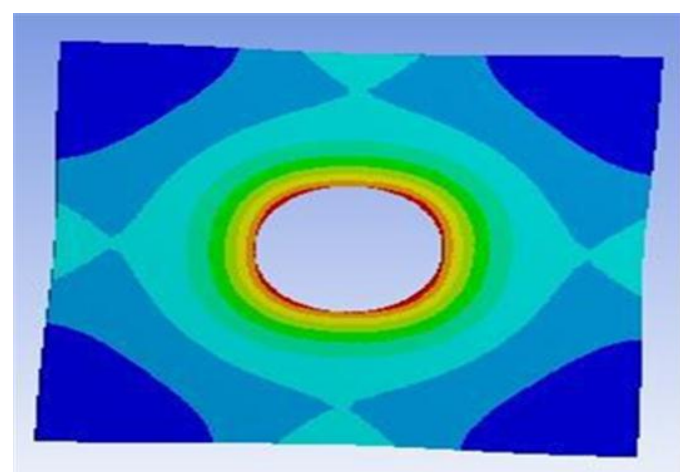

Fig: 100\% Loading (13.632 KPa max) 
Now results for the partial edge loading without cutout are analyzed.

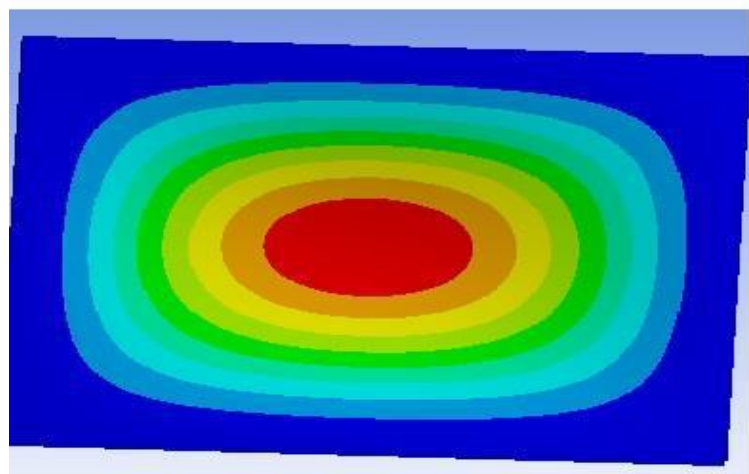

Fig: $100 \%$ loading (3.95 MPa max)

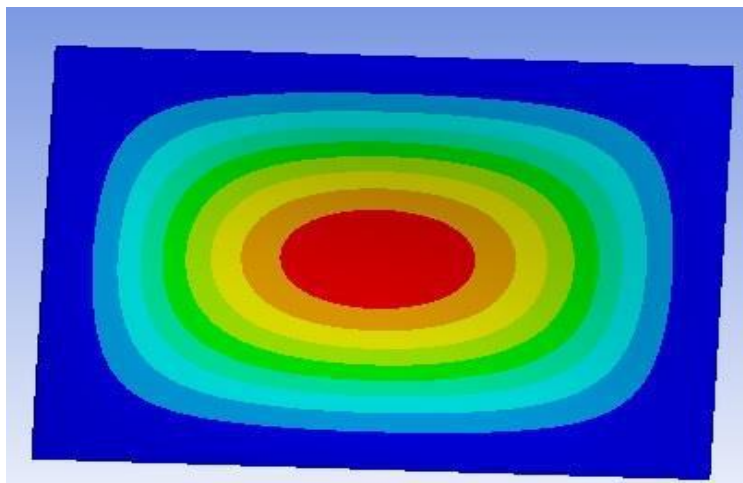

Fig: 80\% Loading (3.84 MPa max)

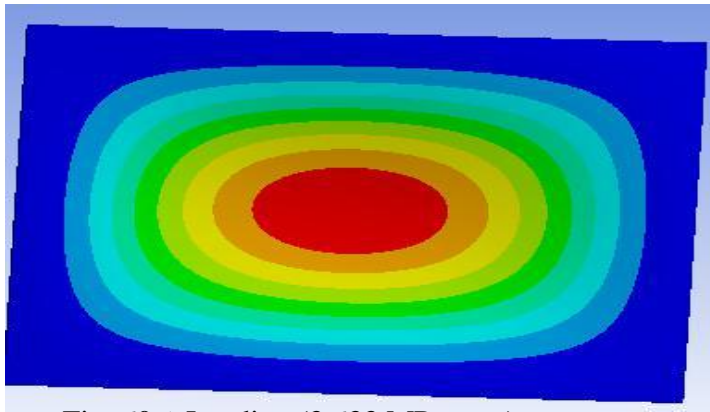

Fig: 60\% Loading (3.633 MPa max)

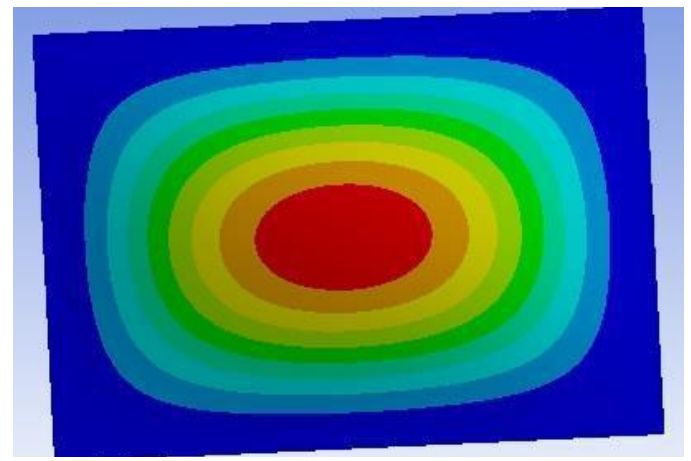

Fig : 20\% Loading (3.116 MPa)

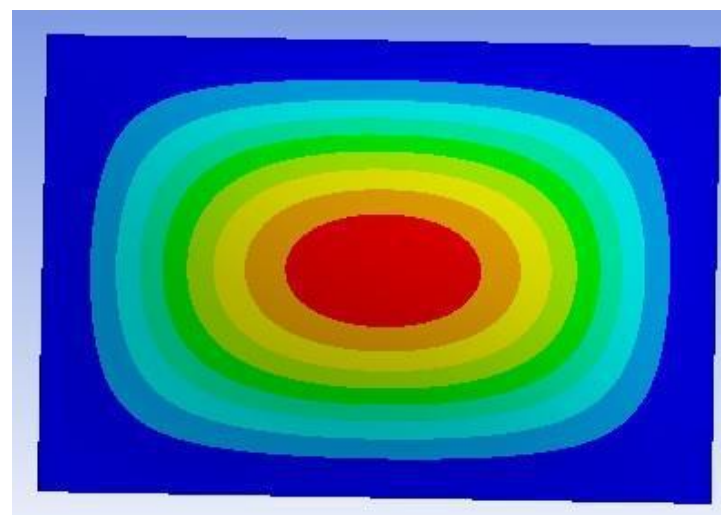

Fig: 40\% loading (3.572 $\mathrm{MPa})$

\begin{tabular}{|l|l|l|l|}
\hline $\begin{array}{l}\text { Initial applied } \\
\text { load } \\
\mathrm{N} / \mathrm{m}\end{array}$ & $\begin{array}{l}\text { \%age loading } \\
\text { of edge }\end{array}$ & \multicolumn{2}{|l|}{ Stress generated } \\
\cline { 3 - 4 } & & $\begin{array}{l}\text { With cutout } \\
(\mathrm{KPa})\end{array}$ & $\begin{array}{l}\text { Without } \\
\text { cutout }(\mathrm{MPa})\end{array}$ \\
\hline 5 & 20 & 13.536 & 3.416 \\
\hline 2.5 & 40 & 13.239 & 3.572 \\
\hline 1.66 & 60 & 13.791 & 3.633 \\
\hline 1.25 & 80 & 13.587 & 3.84 \\
\hline 1 & 100 & 13.632 & 3.95 \\
\hline
\end{tabular}

Table 2:- Buckling Load for SSSS plate subjected to full and partial edge loading in uniaxial loading for type $-\mathrm{I}$ for $\mathrm{b} / \mathrm{h}=100$ 
International Advanced Research Journal in Science, Engineering and Technology

Vol. 2, Issue 5, May 2015

\section{CONCLUSION}

For Simply Supported (SSSS) plates type-1 loading it is clearly shown that stress generated is more in plate with cut out than plates without cutout. The variation in stress generated within plates with cutout and without cutout is very minimal.

\section{REFERENCES}

[1]. P. Sundersen, G. Singh and V. Rao (1998) "Buckling of moderately thick rectangular composite plates plate under partial edge loading" Int. J. of Mechanical Sciences, Vol 40, No11, pp: 1105-1117

[2]. Ghannadpour and Najafi (2008) "On the buckling behavior of crossply laminated composite plates due to circular/elliptical cutouts" Composite Structures, Vol 75, pp 3-6 